\title{
OBRAS Y NOTICIAS DE PARIS BORDON EN ESPAÑA
}

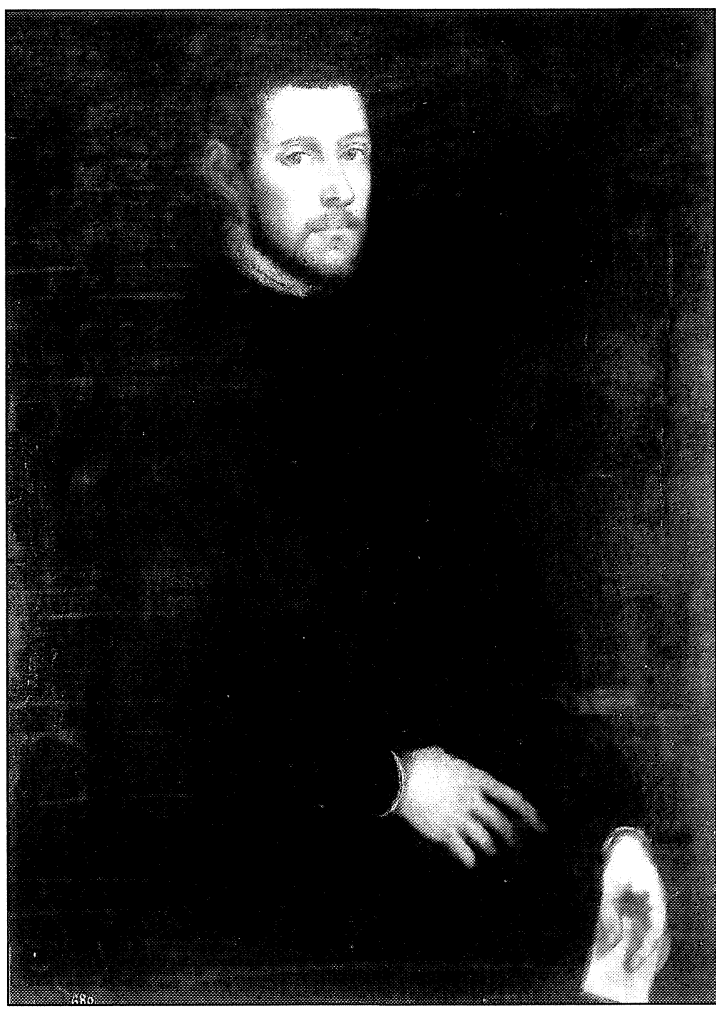

Fig. 1. Anónimo veneciano del siglo xvi. Retrato. Madrid. Museo del Prado.

Si dejamos a un lado el «Retrato de una joven» de la Colección Thyssen-Bornemisza - desde hace poco en nuestro país y creído por la crítica de su mano- ${ }^{1}$, las otras dos obras que hasta el momento se han relacionado en España con Paris Bordon a mi juicio no le pertenecen; se trata de un supuesto «Autorretrato» (Museo del Prado) y de una «Psiquis» (Palacio de Liria), considerada por Tormo ${ }^{2}$ obra notable.

En cuanto al supuesto «Autorretrato» (L. $104 \times 76)^{3}$ (Fig. 1), fueron Allende-Salazar y Sánchez Cantón quienes identificaron al retratado con Paris Bordon basándose en el parecido que sin duda tiene con la efigie publicada en Le Maraviglie dell'Arte... de Ridolfi $(1648)^{4}$, parecido que sin embargo no creo que permita la identificación. Más discutible aún resulta su actual atribución en el Catálogo del Museo del Prado a dicho pintor pues, si bien posee un aire intimista y melancólico que no le es ajeno, muestra una factura más deshecha y grumosa de lo que es habitual en él. Tampoco convence totalmente su atribución a Tintoretto - presente en antiguos catálogos del Museo ${ }^{5}$, negada por Osmaston ${ }^{6} \mathrm{y}$ recientemente vuelta a aceptar por P. Rossi ${ }^{7}$-, ya que la pincelada de éste último resulta más vivaz, decidida y segura. Debido a su mal estado de conservación, pudiera tener razón Berenson ${ }^{8}$ al considerarlo tal vez un original de Tintoretto desigual y estropeado. Con todo, creo que por el momento resulta más prudente incluirlo entre las pinturas anónimas venecianas del siglo XVI.

\footnotetext{
1 Véase Canova, G., Paris Bordon, Venecia, 1963, p. 105, y Pita Andrade, J.M. y Borobia Guerrero, M. del Mar, Maestros Antiguos del Museo Thyssen-Bornemisza, 1994 (tercera edición), p. 211 ( $\mathrm{n}^{\circ}$ 55).

2 Tormo, E., «La Sociedad de Excursiones en el palacio de Liria», Boletín de la Sociedad Española de Excursiones, 1915, T. XXIII, p. 71. Anteriormente A. M. de Barcia -Catálogo de la colección de pinturas del Excmo. Sr. Duque de Berwick y Alba, Madrid, 1911, pp. 121 - 122 ( $\mathrm{n}^{\circ}$ 124) - la había catalogado a nombre de Pordenone, atribución que tampoco convence.

No quisiera dejar de recoger que Camón Aznar, J. (Guía abreviada del Museo Lázaro Galdiano, 1960, pp. 7-8) cita en el Vestíbulo del Museo Lázaro Galdiano: «un lienzo atribuido a Paris Bordone y obra seguramente de Jacobo de Empoli». Muy posiblemente se trate de la «Estigmatización de San Francisco», cuadro conservado hoy en el Salón central (véase Pérez Sánchez, A.E., Pintura italiana del siglo XVII en España, Madrid, 1965, p. 516).

${ }^{3}$ Museo del Prado. Inventario General de Pinturas. I La Colección Real, Madrid, 1990, p. 193 , n 680 (inv. act. n 372 ) (en la ficha del inventario de 1857 figura a nombre de Tiziano y en la del inventario actualizado como obra de Paris Bordone) .

${ }^{4}$ Allende-Salazar, J. y Sánchez Cantón, F. J., Retratos del Museo del Prado. Identificación y Rectificaciones, Madrid, 1919, pp. 49-50.

5 Cf. Museo del Prado. Catálogo de las Pinturas, 1996, p. 32.

${ }^{6}$ Osmaston, F.P.B., The Art and Genius of Tintoretto, Londres, 1915, Vol. II, p. 213.

${ }_{7}$ Rossi, P., Tintoretto. I ritratti, Milán, 1990 ( $1^{\mathrm{a}}$ edic. 1974), p. 94 ( $\mathrm{n}^{\circ}$ 72). También F. Checa -Tiziano y la monarquía hispánica, Madrid, 1994, p. 280-281 ( $\left.\mathrm{n}^{\circ} 75\right)$ - lo incluye entre las obras de dicho pintor.

8 Nota manuscrita conservada en el Archivo del Museo del Prado.
}

$A E A$, LXXVII, 2004, 306, pp. 171 a 201 
Como supusieron Allende-Salazar y Sánchez Cantón, debido a que, como puede apreciarse, tuvo antes forma ovalada, es sin duda uno de los «564-569- 6 retratos del Ticiano vara de alto 3 quartas de ancho (traducido a centímetros $83,5 \times 63$ ) molduras negras a 100 dus. cada vno», que figuran en el inventario del Alcázar de 1666 en la Galería del Mediodía y de los que se sabe, por el inventario del Palacio Nuevo de 1772 -en donde se les cita con otros dos más en la «Antecamara de $\mathrm{S} . \mathrm{M}$ »que fueron transformados en cuadros rectangulares: «42 - 45 - 85 (?) - 39 (?) - 46 118 - 39 - 39 ocho retratos iguales de mas de medio cuerpo originales de Ticiano que el vno es el mismo otro el de su muger y los demas otros sugetos que se ignoran de vara y quarta de alto y vara de ancho (traducido a centímetros $104,5 \times 83,5)=$ Nota al margen todos estos retratos en los primeros inventarios consta haber estado en óbalo pero despues se pusieron en quadro» ${ }^{9}$.

En cambio, en la iglesia de San Juan de Rabanera de Soria se conserva una pintura de «El Salvador» (T. 119,5 × $83 \mathrm{cms})$ (Fig. 2) que, aunque hasta el momento no

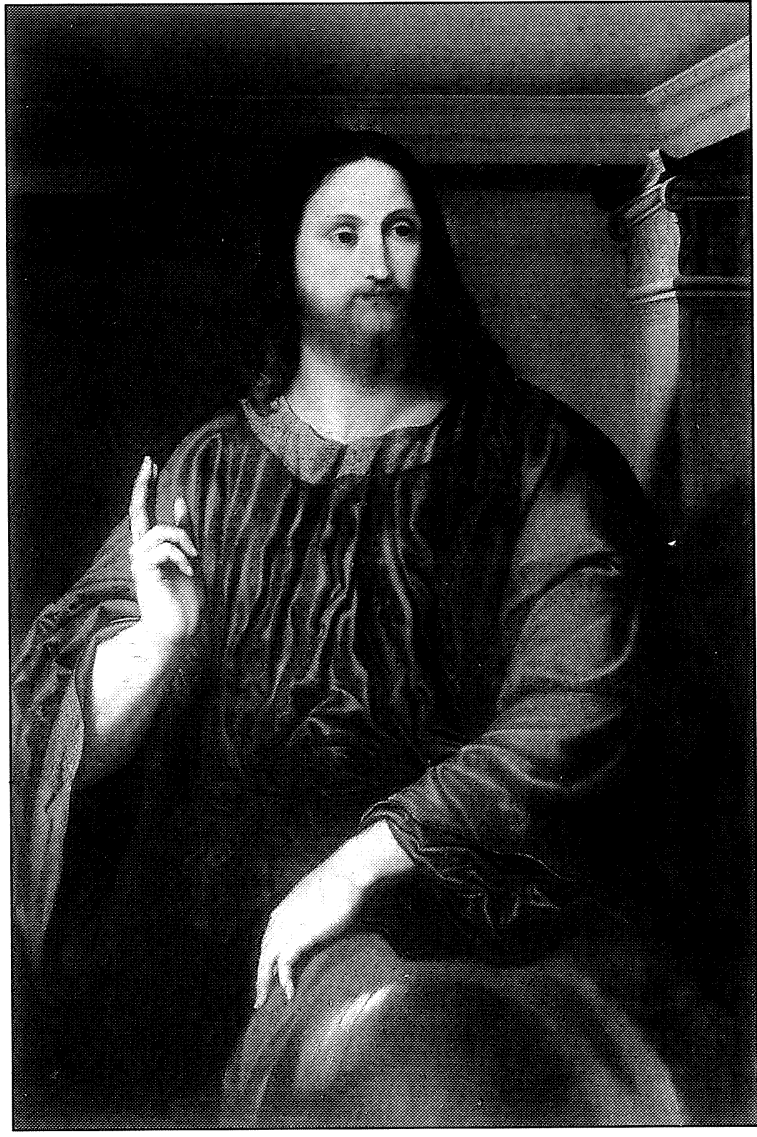

Fig. 2. Paris Bordon. El Salvador. Soria. Iglesia de San Juan de Rabanera. se haya puesto en relación con nuestro pintor, todo hace pensar que le pertenezca. En 1928 Taracena y Tudela la supusieron obra de «escuela veneciana pintada en la primera mitad del siglo XVI» ${ }^{10}$. Por su parte, Cabré Aguiló la consideró de escuela italiana e hizo alusión a la existencia de «reproducciones idénticas de este Salvador por varias parroquias de la provincia» ${ }^{11}$. Recientemente De la Plaza ha señalado que «opiniones de eminentes especialistas recogidas de viva voz a su paso por Soria coinciden en situar la pintura en torno al mundo veneciano: han sonado nombres como el de Bonifacio de Pitati ...., pero no de modo concluyente, sino como una aproximación» ${ }^{12}$.

\footnotetext{
${ }^{9}$ Allende-Salazar, J. y Sánchez Cantón, F.J. (op. cit., 1919, pp. 49-50). Además, ignoro con qué fundamento, dicen que es en el inventario de 1747 donde consta que se les dio su actual forma, ya que, por mi parte, no he encontrado referencia a dicha transformación anterior al inventario de 1772 . Sobre la pertenencia de este retrato a una galería de pintores traída quizás por Velázquez de Italia y sobre la identificación de los restantes retratos, véase también idem, pp. 98-99.

Por otra parte, se siguen citando los seis retratos con las mismas medidas en el mismo lugar en el inventario de 1686 (Bottineau, Y. - quien informa de su presencia en los inventarios de 1666 y de 1700-, "L'Alacazar de Madrid et l'inventaire de 1686. Aspects de la Cour d'Espagne au xvıe siècle», Bulletin Hispanique, 1958, T. LX, nº 2, p. 151-152) y de 1700 , en éste con él número 58 y valorados en cincuenta doblones cada uno (Fernández Bayton, G., Inventarios Reales. Testamentaria del Rey Carlos II, 1701-1703, 1975, Vol. I, p. 24).

Checa (1994, pp. 280-281) propone la identificación de nuestro retrato con otro atribuido a Tintoretto que figura en otros asientos de los mismos inventarios, identificación que parece difícil de aceptar.

${ }_{10}$ Taracena, B. y Tudela, J., Soria. Guía artística de la ciudad y su provincia, Soria, 1928, p. 105.

${ }^{11}$ Catálogo monumental de Soria y su provincia (inédito), cf. De la Plaza Santiago, F. J. (autor de la ficha), Cat. Exp. «La Ciudad de Seis Pisos. Las Edades del Hombre», Burgo de Osma, 1997, p. 268.

${ }_{12}$ De la Plaza Santiago, F. J., op. cit., 1997, p. 268.
} 
Como ha sido puesto de manifiesto por la crítica, no hay duda de que se trata de una obra italiana. Además, todo parece apuntar, como se ha avanzado, hacia Paris Bordon, ya que suya es tanto la manera nerviosa de realizar los abundantes y quebrados pliegues de las vestiduras, claramente marcados y profundamente sombreados en su interior, como la expresión melancólica y ensoñadora del Salvador, que bendice con aire absorto. Asimismo, le es propio su colorido resplandecientemente acerado; piénsese, en particular, en el vivo rojo con reflejos amarillentos de la túnica del Salvador. Por otra parte, la amplitud y desenvoltura de su gesto, que algo tiene de serena majestad y severidad romana, no resulta ajeno a Pordenone, pintor que influyó poderosamente en Bordon. Curiosamente nuestro Salvador también recuerda en cierta manera al Cristo que Lotto pintara en su cuadro de la «Mujer adúltera» (Museo del Louvre, Paris) ${ }^{13}$.

Se conocen varias imágenes de Jesús, algunas firmadas y otras atribuidas a Bordon, que pueden relacionarse con el cuadro soriano, aunque de ninguna de ellas dependa de manera evidente o sea un clara derivación. En dos de ellas - las conservadas en sendas colecciones privadas, una de Florencia y otra de Milán - también apoya Nuestro Señor su mano izquierda en una esfera ${ }^{14}$.

Muy probablemente haya que situar su ejecución alrededor de 1540, ya que la posición ligeramente girada de Cristo, cuyo brazo izquierdo se coloca en primer término y algo más retraído el derecho, recuerda a la del retrato fechado en dicho año de «Jerónimo Krafft» (Museo del Louvre, Paris), incluso resultan muy semejantes la mano izquierda de ambas figuras. Asimismo, el tratamiento de los pliegues todavía no manifiesta esa multiplicación obsesiva presente en obras tardías. Por otra parte, también resulta típico del Bordon de los años 40 el hecho de encajar a Cristo en un angosto espacio arquitectónico iluminado por una luz alta lateral ${ }^{15}$.

Aunque se desconozca el momento en que llegó a España, todo hace suponer que fuera en fecha temprana, ya que el Museo de la catedral de Burgo de Osma cuenta con dos copias antiguas, casi sin duda realizadas en España. Respecto a una de ellas, dice Arranz - quien la pubica sin aludir a su condición de tal - que en un principio era la pintura central del Retablo de la Sacristía de la Capilla de Santiago de la Catedral y que fue donada por el prior Sarmiento, como se desprende del siguiente asiento del inventario de dicha capilla de 1568: «Item otro Retablo del Salvador que está asentado en el altar de la Sacristía» ${ }^{16}$; de ser ello cierto, el original soriano debió llegar a España con anterioridad a dicha fecha. Por su parte, De la Plaza avanzó la hipótesis de que «cabría pensar en una adquisición italiana como la que Arranz Arranz postula que hiciera el prior de la Catedral del Burgo de Osma, don Pedro, en Roma, para gestionar el traslado de los restos de San Pedro de Osma a su nueva capilla, o quizá, más verosímilmente, en un regalo posterior del venerable Palafox a su querida «Escuela de Cris-

\footnotetext{
13 Según la crítica obra realizada a inicios de la década de 1530 (Palluchini, R. y Mariani Canova, G., L'opera completa del Lotto, Milán, 1974, pp. 111 y 114).

14 Las firmadas son: «El Redentor bendiciendo» (L. 73,5 × $64 \mathrm{cms}$ ) (Maritshuis, La Haya), «Cristo bendiciendo» (L. $90 \times 73$ ) (National Gallery, Londres); las atribuidas: «El Redentor» (L. $86 \times 57 \mathrm{cms}$ ) (Galleria dell'Accademia, Ravenna) (Canova, G., op. cit., 1963, pp. 79, 80, 110-111 y láms 65, 66, 64) , «Cristo bendiciendo» (Colección privada, Florencia), «El Salvador» (T. $70 \times 52 \mathrm{cms}$ ) (Catedral, Ragusa) (Gamulin, G., « «Il Redentore» di Paris Bordone nella cattedrale di Ragussa (Dubrovnik), Arte Veneta, 1958, año XII, pp. 192-194) y «Cristo bendiciendo» (T. $75 \times 61 \mathrm{cms})($ Colección privada, Milán) (Sgarbi, V., «La mostra di Paris Bordon a Treviso», Arte Veneta, 1984, año XXXVIII, p, 255).

Por su parte, Bailo, L. y Biscaro, G., al hablar del «Redentor bendiciendo» de La Haya, señalan otros Redentores, hoy desaparecidos, supuestamente de Paris Bordon, ninguno de los cuales parece coincidir con el soriano (Della Vita e delle Opere di Paris Bordon, Treviso, 1900, p. 110, $\mathrm{n}^{\circ}$ 1).

15 Véase lo dicho por Mariani Canova a propósito de la «Flora» del Louvre (en Cat. Exp., Paris Bordon, Treviso, 1984, p. 80).

16 Arranz Arranz, J., El Renacimiento sacro en la Diócesis de Osma-Soria, Burgo de Osma, 1979, vol. I, pp. $398-399$.
}

$A E A$, LXXVII, 2004, 306, pp. 171 a 201 
to», aunque de nada de ello exista constancia escrita» ${ }^{17}$.

En el Museo del Prado se conserva una «Flora» (L. 100 x 80 cms) ${ }^{18}$ (Fig. 3), que es una buena copia, de técnica cercana a Paris, que sigue con mucha precisión el original conservado en el Museo del Louvre $(\text { L. } 103 \times 85)^{19}$. Su factura resulta algo dura y seca, aunque hay que confesar que la suciedad que la recubre dificulta su apreciación.

En el inventario de la quinta del duque del Arco de 1789 se menciona en la «Pieza octaba de Salon»: «229 (número que sigue conservando el cuadro en su ángulo inferior izquierdo) Otro (cuadro, se entiende) de cinco quartas de alto y vara de ancho (traducido a centímetros $105 \times$ $83,5 \mathrm{cms})$ : representa una Flora: en .......100» ${ }^{20}$. Muy posiblemente con anterioridad perteneció al marqués de Leganés, ya que pudiera corresponder al siguiente asiento de su in-

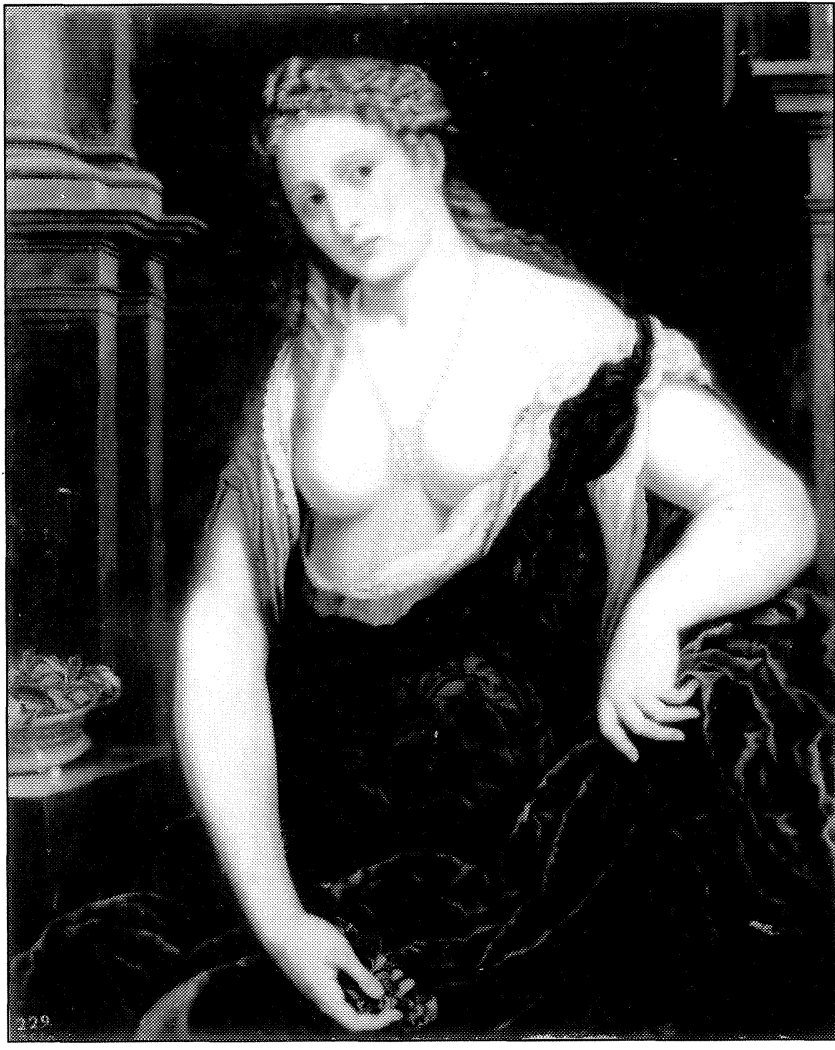

Fig. 3. Paris Bordon. Copia. Flora. Madrid. Museo del Prado. ventario de 1655: «un medio cuerpo de muger con unas flores en la mano y una çesta con flores, despechugada, de mano de tiçiano, en 1.200 (reales, se entiende)» ${ }^{21}$.

A juzgar por la cantidad de referencias a obras posiblemente atribuidas a Paris Bordon en publicaciones e inventarios antiguos, muchas debieron de ser las obras supuestamente suyas en manos de españoles o de personajes muy directamente vinculados con España. Antes de seguir adelante, se ha de precisar, sin embargo, que la existencia de tres pintores con nombres muy semejantes: Paris Bordon, Giovanni Antonio de' Sacchis, llamado il Pordenone, y Sébastien Bourdon, hace a veces difícil saber a cuál de ellos se refieren algunas menciones antiguas. Por ello, se ha optado por recoger a continuación sólo las menciones que más claramente parecen referirse a Paris Bordon.

En el mismo siglo XVI, dice Vasari al hablar de nuestro pintor: «In Fiandra mandò due altri bellissimi quadri: una Santa Maria Madalena nell' eremo, accompagnata da certi Angeli; ed una Diana che si lava con le sue Ninfe in un fonte; i quali due quadri gli fece fare il Candiano

\footnotetext{
17 De la Plaza Santiago, F. J. (autor de la ficha), Cat. Exp. cit., 1997, p. 268.

${ }^{18}$ Museo del Prado. Inventario General de Pinturas. I La Colección Real, Madrid, 1990, p. 666 , n. ${ }^{\circ} .540$ (inv. act. n. ${ }^{\circ}$ 3.576) (en las fichas de los inventarios de 1857 y actualizado figura como copia de Tiziano y se le titula «La Hermosura»).

${ }^{19}$ Mariani Canova, G. (autora de la ficha) Cat. Exp. Paris Bordon, Treviso, 1984, p. 80.

20 Fernández-Miranda, F., Inventarios Reales. Carlos III, 1789-1790, Madrid, 1989, T. II, p. 479.

${ }^{21}$ López Navío,J., «La gran colección de pinturas del Marqués de Leganés», Analecta Calasanctiana, 1962, nº 8, p. 272. No puede tratarse de la «Flora» de Tiziano (Galleria degli Uffizi, Florencia), ya que en ésta no figura cesta alguna y la diosa sólo está muy ligeramente despechugada. Además, la «Flora» de Tiziano la vendió en 1639 Alfonso López al Archiduque Leopoldo Guillermo y fue enviada en 1793 a Florencia en un intercambio de pinturas entre austríacos y florentinos(cf. Wethey, H., The Paintings of Titian.III Mythological and Historical Paintings, Londres, 1975, p. 154).
} 
milanese, medico della reina Maria, per donargli a Sua Altezza........Andato poi Paris a Milano, .... Nel medesimo tempo dipinse molte favole d' Ovidio al Marquese d' Astorga, che le portò seco in Ispagna» ${ }^{22}$. Desgraciadamente nada se sabe de las dos pinturas que debieron formar parte de la colección de María de Hungría, ni de las que hizo para el marqués de Astorga.

Entre las pinturas compradas en Inglaterra por el conde de Fuensaldaña (posiblemente durante 1651) y enviadas a España se cita: «Mas otra pieca que es la historia de Joseph y la muger de Putifer de mano de Paris Bordon fs. 180» ${ }^{23}$. En enero de 1686 el marqués del Carpio envió a España en el bajel Llorel (caja $N^{\circ}$ 12. T.): «Una Nra Sra con el Niño Jesus en Braço San Joseph y el Presepio con un Pastor de rodillas con el $\mathrm{N}^{\circ}$ 517. de mano de Paris Bordon de palm. 2. y $11 / 2$ con corniça dorada.», y en julio del mismo año en el bajel Lagoun: «Un quadro en tela que representa S. Geronimo de mano de Paris Bordon sin Num. ${ }^{\circ} \gg{ }^{24}$. El primer cuadro no debió llegar a España, pues, como supuso Pérez Sánchez, es muy posible que se hundiera el bajel Llorel ${ }^{25}$. En cuanto al segundo, pudiera corresponder al bellísimo cuadro de «San Jerónimo en un paisaje» (L. $70.2 \times 87 \mathrm{cms}$ ) del Philadelphia Museum of Art (colección de John G. Johnson), del que se sabe que en 1851 formaba parte de la colección Leuchtenberg de $\mathrm{Mu}$ nich ${ }^{26}$. En el inventario de 1688, siempre del mismo marqués, se menciona en la «Pieza terzera» del «Jardin de Sn Joachin» una pintura de «Vodon», con el número de inventario 29, de «nra Sra. Con El niño Jhs en brazos senttada Sobre Tres gradas de Piedra Con San Roque Santta Catha. Santa Margaritta», pintura que medía una vara de alto por $1 \frac{1 / 4}{4}$ de ancho y se valoraba en 3.300 reales ${ }^{27}$. En una lista, fechada en Madrid el 16 de octubre de 1694 y dirigida por Wiser al Elector Palatino, de «Cuadros comprados por S.A.E. después de enviar la lista anterior» figura: «Un Salvador, en lámina, que parece de Paris Bordone ...... I (dobla)» ${ }^{28}$. Entre las pinturas que se libraron del incendio del Alcázar y que se recogen en el inventario del Real Palacio de Madrid de 1734 se menciona: «288 - Otro de vara y quarta de alto y vara de ancho con marco negro de vn retrato de vn hombre de medio cuerpo original de Bordon» ${ }^{29}$. Durante la francesada se cedió al general Sebastiani una Sagrada Familia de Bordone ${ }^{30}$.

Tras la muerte de Carlos IV, entre sus pinturas enviadas de Roma figuraban dos atribuidas a nuestro pintor: «43 Sta Familia p.r Paris Bordon, discipulo de Tiziano, alto 3 p. 5 p. ancho 4 p. 5 p. Bueno» y «161 Quadro de Devocion con una Sta Familia, S.n Andres, y S.n Jeronimo, p.r Paris Bordon, alto 2. p. 4. p. ancho 3 p. 1. p. Bueno» ${ }^{31}$. Además, en 1837 el marqués de las Marismas poseía otras dos: «PARIS BORDOGNI / Né à Turin en 1500, mort en 1570. / 145. Apollon écoutant Midas. / Haut., 3 pieds 6 p.; Larg., 2 pieds 8 p.(traducido a centímetros 112,2

${ }^{22}$ Vasari, G. (ed. Milanesi), Le Vite de'più eccellenti pittori, scultori ed architettori, Florencia, 1981 (nueva impresión de edic. 1906 (basada en segunda edición original 1568)), Vol. VII, p. 464 - 465.

${ }^{23}$ Vergara, A., «The Count of Fuensaldaña and David Teniers: their purchases in London after the civil war», The Burlington Magazine, 1989, febrero, p. 132.

${ }^{24}$ «Memoria de los Numeros puestos a las caxas que se embiaron à España con los dos vaxeles Ingleses llamado el uno, llorel ... y el otro Lagoun ... en todo el mes de Henero de 1686 en Napoles ...»

«Memoria de los Numeros puestos à las caxas ... con el vaxel llamado Lagoun Merchant Ingles, ... en todo el Mes de Julio de 1686 en Napoles ...» (Manuscritos conservados en la Biblioteca del Monasterio de El Escorial).

${ }_{25}$ Pérez Sánchez, A. E., «Sobre la venida a España de las colecciones del Marqués del Carpio», Archivo Español de Arte, 1960, pp. 293-295.

${ }^{26}$ Mariani Canova, G. (autora de la ficha), Cat. Exp. The Genius of Venice, Londres, 1983, pp. 155-156.

27 Burke, op. cit., 1984, Vol. II, pp. 252b.

${ }_{28}$ Herrero García, M., Contribución de la Literatura a la Historia del Arte, Madrid, 1943, p. 85.

${ }^{29}$ Inventario general de todas las Pinturas que se han libertado en el incendio. Real Palacio de Madrid. 1734 (Manuscrito).

${ }^{30}$ Véase al respecto Madrazo, P., Viaje artístico de tres siglos por las Colecciones de cuadros de los Reyes de España, Barcelona, 1884, p. 299 y Hempel Lipschutz, I., «El despojo de obras de arte en España durante la Guerra de la Independencia», Arte Español, 1961, p. 265.

${ }^{31}$ Ynventario de los Quadros antiguos, y modernos del Señor Dn Carlos IV ..... (Manuscrito fechado el 11 de febrero de 1819 y conservado en el Ministerio de Asuntos Exteriores).

AEA, LXXVII, 2004, 306, pp. 171 a 201 
$\times 84,8) » y$ «PARIS BORDOGNI / 203. Vénus et l' Amour. / Haut., 2 pieds 4 p.; Larg., 4 pieds 4 p.( traducido a centímetros $74,8 \times 139,6) »{ }^{32}$. Por lo que respecta al primer cuadro, sus medidas no difieren mucho de las del «Apolo entre Marsias y Midas» ( L. $98 \times 81 \mathrm{cms}$ ) que existió en la Gemäldegalerie de Dresde, del que se conoce su procedencia desde el siglo XvIII. Pudiera tratarse de una copia de éste, quizás la «redazione (del cuadro de Dresde, se entiende) più scarsa e forse non autografa» que en 1953 se encontraba en venta en la Galleria G. Cramer de la Haya ${ }^{33}$. En cuanto a la Venus y Cupido, tal vez corresponda al cuadro del mismo asunto conservado actualmente en el Muzeum Narodowe de Varsovia, de medidas muy similares (L. 95 $\times 143$ ) y del que se conoce muy poco sobre su procedencia, o la copia de éste que se conservó o quizás se siga conservando en la colección Engel de Viena ${ }^{34}$. Años después, en la subasta de los cuadros de dicho marqués de 1843 consta: «BORDONE (PARIS), né à Trévise en 1500, mort en 1570. / 267. - Apollon chez les pâtres./ Il est accoudé sur un rocher, dans l'attitude de la méditation et tenant de la main droite une lyre; deux bergers sont vus derrière lui, l'un à droi-

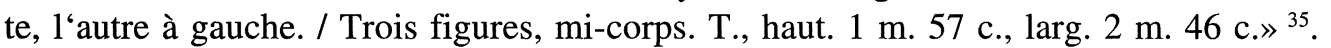

José MARÍA Ruiz MANERo

\section{UN PROYECTO NO REALIZADO DE FRANCISCO SABATINI PARA EL RETABLO MAYOR EN LA IGLESIA DE SAN CAYETANO DE MADRID}

La inédita documentación encontrada en el Archivo General de Simancas (A.G.S.), Secretaría y Superintendencia de Hacienda, leg. 943, permite afirmar que Sabatini realizó varias trazas ${ }^{1}$ para levantar el retablo mayor en la iglesia de los Teatinos de Madrid, también conocidos como Clérigos Regulares de San Cayetano. El proyecto no llegó a ejecutarse, si se hubiera realizado constituiría una de las grandes aportaciones de este arquitecto italiano en nuestro país. $^{2}$

La nueva iglesia de San Cayetano se encontraba bajo patronato real, de ahí que tras su finalización arquitectónica en $1761^{3}$, las obras del retablo mayor tuviesen que ser costeadas por Carlos III. El monarca encargó la construcción a su arquitecto de confianza, Francisco Sabatini, que debió realizar varios planos, escogiéndose un único diseño. Se ignora con exactitud

\footnotetext{
${ }^{32}$ Notice des tableaux des écoles espagnoles, italienne, flamande, française et allemande, exposés dans la Galerie du Marquis de las Marismas, París, 1837, pp. 46 y 57.

33 Véase Canova, op. cit., 1963, p. 118.

34 Véase Canova, op. cit., 1963, pp. 114 y 132.

${ }^{35}$ Catalogue des tableaux anciens des Ecoles espagnole, italienne, flamande, .... composant la Galerie de M. Aguado, Marquis de las Marismas dont la vente aux enchères publiques aura lieu par suite de son déces, .... a Paris ...., Paris, 1843, p. 59.

${ }^{1}$ «La Comunidad de Clérigos Regulares de San Cayetano de Madrid (...) hace presente que V.M. tiene mandado hacer varios diseños para construcción del retablo del altar mayor de su yglesia de los que se halla aprobado uno», (A.G.S. Ibid., leg. 943).

${ }^{2}$ Sobre el templo de los Teatinos puede verse el exhaustivo estudio de Matilde Verdú Ruiz, «Intervención de Pedro de Ribera en la iglesia y convento de San Cayetano, en Madrid». Academia. Boletín de la Real Academia de Bellas Artes de San Fernando. Madrid, segundo semestre de 1993, n ${ }^{\circ} 77$, pp. 403-439, recopilando la bibliografía existente hasta ese año (págs. 438-439); de la misma autora puede verse la monografía de Pedro de Ribera. Madrid, Instituto de Estudios Madrileños, 1998. Asimismo y sobre el artista italiano nos remitimos al catálogo de la exposición de Francisco Sabatini, 17211797. La arquitectura como metáfora del poder. Madrid, 1993.

${ }^{3}$ Previamente, el 12 de noviembre de 1755, Manuel López Corona, maestro de obras, informa sobre los reparos que deben ejecutarse en el templo de San Cayetano, tras el terremoto de Lisboa acaecido durante el 1 de noviembre de ese mismo año.
}

AEA, LXXVII, 2004, 306, pp. 171 a 201 